\title{
Catasetum maranhense, um novo hospedeiro de Sphenospora kevorkianii (Uredinales)
}

\author{
Gilson Soares da Silva ${ }^{1}$, Mário Barreto Figueiredo²
}

\begin{abstract}
${ }^{1}$ Universidade Estadual do Maranhão, Departamento de Fitotecnia e Fitossanidade, 65001-970, São Luís, MA <gilson_soares@uol.com.br>; ${ }^{2}$ Instituto Biológico, Av. Rodrigues Alves, 1252, 04014-002, São Paulo, SP.

Data de chegada: 22/07/2005. Aceito para publicação em: 03/10/2005.
\end{abstract}

Entre as orquidáceas que ocorrem no Estado do Maranhão, o gênero Catasetum destaca-se como o de maior distribuição geográfica e também em número de espécies (6). Dentre as espécies, C. maranhense Lacerda \& Silva, 1998, é um das mais freqüentes, ocorrendo em todas as regiões onde há abundância de palmeira babaçu.

Em meados de 2004, foram coletadas, no município de Fernando Falcão, Maranhão, folhas de C. maranhense, crescendo sobre babaçu (Orbgnya phalerata Martius) com inúmeros soros amarelos, pulverulentos (Fig. 1). Posteriormente, material idêntico foi coletado no município de Brejo no mesmo estado. O exame microscópico do material revelou a presença de uredínios hipófilos, sub-epidérmicos em origem, depois irrompentes. Urediniosporos marrom-amarelados, medindo $28-33 \times 18-26 \mu \mathrm{m}$, largamente elipsóides ou obvóides, equinulados, poros 1 a 2 , equatoriais. Télios hipófilos, sub-epidérmais, irrompentes, marrom-escuros a negros; teliosporos pedicelados, binucleados de 23-28x 13-16 $\mu \mathrm{m}$, com um poro germinativo apical. Espermagônios e écios desconhecidos. Com essas características, o fungo foi identificado como Sphenospora kervokianii Linder (Fig. 2).

A primeira descrição de $S$. kervokianii foi feita por Linder em 1944 (3) sobre Epidendrum difforme Jacquin proveniente da Nicarágua. No Brasil, S. kervokianii já foi descrito em Cyrtopodium punctatum (L.) Lindl., Notylia lyrata F. Moore, Prescottia sclerophylla Lindley, Stanhopea graveolens Lindley, Zigostates lunata Lindley (1) e, mais recentemente, sobre Pleurotalis mentigena Kraenzl. (5) e Catasetum fimbriatum (4).

Esta é a primeira constatação de S. kervokianii em C. maranhense no Brasil. O material foi depositado no Instituto Biológico de São Paulo, sob o número de campo IBI 2005-14.

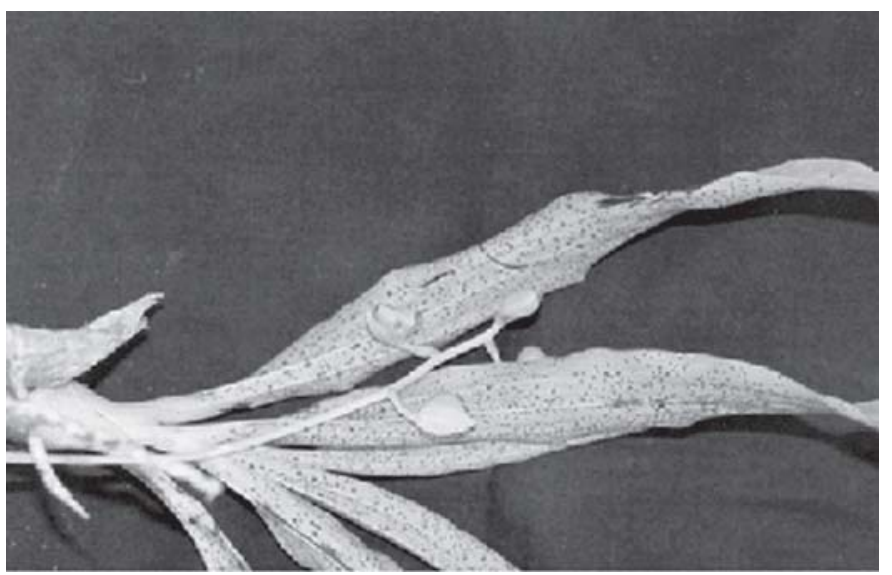

Figura 1. Sintomas causados por Sphenospora kevorkianii em $\mathrm{Ca}$ tasetum maranhense.

\section{AGRADECIMENTO}

Os autores agradecem aos Professores G.B. Cummins e Yasuyuki Hiratsuka pela autorização para utilização da figura $n^{\circ}$ 2.

\section{REFERÊNCIAS BIBLIOGRÁFICAS}

1. Cummins, G. B. Hiratsuka, Y. Illustrated genera of rust fungi. $3^{\text {th }}$ ed. St. Paul,The American Phytopathological Society, 2003, $225 \mathrm{p}$.

2. Hennen, J.F. ; Hennen, M.M.; Figueiredo, M.B. Índice de ferrugens (Uredinales) do Brasil. Arquivo do Instituto Biológico, São Paulo, v.49, Supl. 1, p.1-201.

3. Linder, D.H. A new rust of orchids. Mycologia, v.36, n. , p. 464-468, 1944.

4. Pereira, O. L.;Barreto, R.W. First report of Spherospora kevorkianii (Raveneliaceae) on the orchid Catasetum fimbriatum in Brazil. Plant Pathology, London, v. 53. n. 2, p. 256,2004.

5. Pereira, O.L.; Cavanazzi, J.R.P. ; Rollemberg, C.L. ;Kasuya, M.C.M. Sphenospora kevorkianii, a rust fungus (Uredinales: Reveneliaceae) on the orchid Pleurotalis mentigera. Brazilian Journal of Microbiology, São Paulo, v.33,n.2, p.2002.

6. Silva, J.B.F. ; Silva, M.F.F. Orquídeas nativas da Amazônia Brasileira. Gênero Catasetum L.C. Rick ex Kunnth). Belém, Museu Paraense Emilio Goeldi, 1988, 121 p.

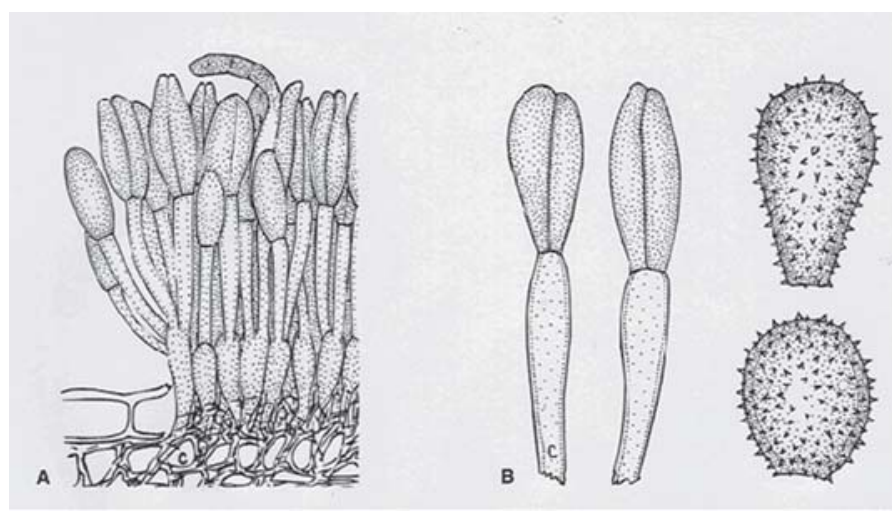

Figura 2. Sphenospora. a. Télio. b. Teliosporos e urediniosporos. 